\title{
Study on Fusion Development of General Education and Specialized Course Education in Universities
}

\author{
Lv pin \\ chongqing university of education 400067 chongqing \\ hunter2011@foxmail.com
}

Keywords: General Education; Specialized Education; Quality Education; Fusion Development.

\begin{abstract}
How to properly handle the relationship between general education and specialized course education, and then promote fusion development of them, is a key issue for comprehensive implementation of quality education and cultivating high quality talents. Fusion development of general education and specialized course education embodies the concept of quality education, and the needs of contemporary higher education development and interdisciplinary personnel training as well. However, because of the misunderstanding of the concept, the discipline barriers and the abuse of the teaching management system, the organic integration of the two is hindered. To solve this problem, we have proposed some strategies to promote the integration of general education and professional education.
\end{abstract}

\section{Introduction}

General education is also called liberal education, which is aiming to cultivating talents with broad vision, liberal spirit and beautiful emotion; professional education is also called specialized education, which is aiming to impart some students with in-depth knowledge and skills. Since birth, general education and professional education continuously kept on interacting, and they are evolving in conflict and interaction. Now under the concept of quality education, we need to review the dialectical relationship between general education and professional education, so as to promote their fusion development, and cultivate the talents with comprehensive quality.

\section{Necessity of Fusion Development}

Requirement of Quality Education Idea. Currently, the idea of quality education has been the important guiding ideology of higher education reform in China. The essence of quality education idea is to improve the quality of people, emphasizes the key function of scientific culture, thought quality and inner quality to the development of man. Quality education reflects the people-oriented education idea, and focus on the comprehensive development of human. While comprehensive development requires an organic combination of general education and professional education, so it is the inevitable requirement for the quality education.

Ways of Cultivating Interdisciplinary Talents. The cultivation of university talents in our country is based on the division of specialty and discipline. However, the developing trend of global economic integration requires people to master the knowledge and skills of many subjects, so that they can complete the complex management issues better. Under this background, the traditional training mode of specialized personnel has some disadvantages. Universities should construct interdisciplinary personnel training system, integrating general education and professional education together, to cultivate talents with multi domain knowledge, and meet the needs of the economic globalization society.

Trend of Contemporary Higher Education. Whether domestic or foreign, general education and professional education are two important parts of higher education, which is equally important and irreplaceable. So how they are interdependent and even achieve fusion development is an important research topic in the field of higher education. Therefore, only effectively penetrating 
them throughout the whole process of higher education can ensure the cultivation of students' full knowledge, abilities and qualities.

\section{Objectives of Fusion Development}

Communion of Knowledge Quality and Moral Character. Ma Jiajue murder, Beijing University poisoning case and other campus crimes are frequently happening, and a lot of such cases occurred in famous universities, with characteristic of high IQ crime. These events have to attract our attention.

Over the years, our higher education has cultivated many highly qualified personnel of knowledgeable and intellectual superior, but the educators are concerned less about the quality of human thought, so the students neglect the cultivation of self good personality and moral character. By fusion development of general education and professional education, allows students to understand that thought, morality and will are as important as knowledge and culture, and regard independence of personality and noble as success.

Communion of Scientific Literacy and Humanistic Quality. Scientific literacy generally includes scientific thinking, knowledge and spirit. The formation of scientific literacy would help people to better understand the natural world, and learn to use scientific methods to solve practical problems; while humanistic quality corresponds to the knowledge and spirit of the humanities and social sciences.

Science literacy and the humanistic quality are not the opposite concept, but dialectical and unified relations. Actually, the history of human social development also proves that the two are complementary to each other, that is, scientific spirit often contains rationality, truth, goodness and beauty, while faith, tolerance, respect and other sentiments can conversely promote the progress of science. Therefore, universities should not separate the professional education from the general education because of the subject barrier.

Communion of Human Subject Value and Object Value. Human subject value is based on affirmation of human subject status in social activities, so as to realize the individual's pursuit of freedom and ideal value; human object value is to combine people with nature and society, which emphasize the social value of individual. General education is generally to establish the human subject values, and contrarily, professional education is to cultivate more consciousness of object value.

On the one hand, to meet people's own development and inner needs is the highest value of education, is also the modern material civilization and the spiritual civilization development trend. On the other hand, people are dependent on the presence of the group, who need to be served by society and should serve the society at the same time. Therefore, to realize the unity of subject value and object value, we should not only promote individual freedom, but also play instrumental value contributing to social progress.

\section{Problems of Fusion Development}

Theoretical Cognition Deviation. Although the concept of general education and professional education has been proposed since many years ago, there is still a deviation in the current understanding of the relationship between the two kinds of ideas in our country, which this is one of the main reasons why they cannot be well integrated. In order to promote general education courses, some experts regard the professional education curriculum as the obstacle to its popularization; meanwhile, when supporters of professional education conduct teaching reform, they often only takes into account the reform of the professional education, but ignored general education reform.

Barriers between Subjects. Because research objects and research methods of each subject are different, there are some barriers between subjects. Differences in all aspects between liberal academic disciplines and professional disciplines are greatly different, so barriers between the two disciplines are particularly prominent. With the maturity of the education system, many universities 
in china have established various interdisciplinary and comprehensive subjects, but there is still a little connection between general discipline and the discipline of discipline.

The phenomenon of subject barriers is almost there in every university in China. The reason for this phenomenon is, some academic leaders artificially set the threshold, to exclude teaching from other subjects or researchers from other disciplines to enter the subject. In addition, universities are too impetuous in the establishment of new disciplines, without consideration of its joint effect with existing subjects, so inevitably form isolated state in the development process of the discipline.

\section{Strategies of Fusion Development}

Promote Quality Education Concept. Chinese universities should continue to adhere to the core concept of quality education, and vigorously promote people-oriented spirit of education. quality education is a comprehensive educational philosophy, including scientific literacy, moral character, emotional appeal, spirit will, humanistic quality, etc. It will be not difficult to deal with the relationship between general education and professional education as soon as endorse the concept of quality education, and then eliminate understanding deviation on them. From the perspective of overall quality cultivation, general education and professional education are both the important parts of quality education, so university administrators should treat general education and professional education equally.

Break Subject Barriers. To break the subject barriers between general education and professional education it should be realized through the gradual reform of teaching, rather than a short duration of time. First, universities should be fully aware of the shortcomings to the development of science discipline caused by subject barriers; second, in terms of Teacher troop construction, we should strive to avoid "inbreeding"; third, we would better have the courage to break the traditional disciplines philosophy, and on the basis of discipline inherent development law, to strengthen communication between subjects and gradually form a new discipline system.

Improve Teacher Training System. In addition to establishing the quality education concept and breaking subject barriers, fusion development of general education and professional education also depends on the support of teacher training, teaching evaluation and other teaching management system. To establish a sound teaching management system, it should starts from improving teacher training system and improving teaching quality. Currently, teacher training system of general education curriculum is relatively weak, lack of excellent teachers and vivid teaching content, so it is difficult to obtain the same status as the professional course, to say nothing of fusion development.

Reform Credit Management System. In terms of credit management system, students are supposed to obtain sufficient autonomy. First, within a certain range, allow students to reselect their majors. when the students chose their majors at the first time, there is more or less some blindness, but over a period of in-depth learning, they will have more knowledge about the specialty and their own interests, so some student will have the needs for major re-election and we should give them a free choice.

Second, provide students a broader course taking right. Although many universities have set up elective system, student's selection range is still very limited. Universities should be combined with the existing disciplines, to develop more interdisciplinary subjects and marginal discipline, especially integration courses of general education and professional education. In addition, can allow students select courses across grade or major, so realize educational resource sharing as far as possible, which is conducive to fusion development of general education and professional education.

\section{References}

[1] Craig C. Howard: Theories of General Education: A Critical Approach. Published by Macmillan Academic Press, 1993. 
[2] Zhu X, Hui C. Thought of Strengthening Quality Education. Journal of Anshan Institute of Iron \& Steel Technology, 2000.

[3] Tang X L, Xiang-Dong H U, Luo P, et al. Talent Cultivating Mode of Specialized and General Education in Electric Engineering and Automation. Journal of Electrical \& Electronic Education, 2008.

[4] Tang X L, Xiang-Dong H U, Luo P, et al. Talent Cultivating Mode of Specialized and General Education in Electric Engineering and Automation. Journal of Electrical \& Electronic Education, 2008.

[5] Tao M Z, Yang X Q. Integration of General Education and Specialized Education_-Development of Disciplinary Programs at Agricultural Universities in the New Era[J]. Education \& Modernization, 2007.

[6] Huang H. Dilemma and Breakthrough in China's General Education. Modern Education Management, 2014. 